\title{
Aortic dissection causing embolic stroke
}

\author{
E. Fernandez, Raghunandhan Nadig, Thomas Mathew, G. R. K. Sarma \\ Department of Neurology, St. Johns Medical College and Hospital, Bangalore - 560 034, India
}

A 45-year-old female, known hypertensive for the past five years, presented with an episode of generalized seizure. She also had diffuse headache and mild retrosternal chest pain just few hours prior to the episode of unconsciousness. On examination, pulse was $68 \mathrm{~min}$, normal rhythm, volume, character, and all peripheral pulses were well felt and blood pressure was $170 / 100 \mathrm{mmHg}$. Cardiac auscultation revealed early diastolic murmur in the right parasternal area. On neurological examination the deep tendon reflexes were exaggerated and plantar were bilaterally flexor, and tandem gait was ataxic. Diffusion-weighted magnetic resonance imaging (MRI) of brain revealed multiple small hyperintense lesions involving bilateral subcortical areas and cerebellar white matter, suggesting acute embolic infarcts [Figure 1]. Transthoracic echo cardiogram revealed dilated ascending aorta and an intimal flap suggestive of dissection. MR aortogram confirmed the same, the dissection extending from ascending aorta till bifurcation of aorta [Figure 2]. Her carotid and vertebral arteries were normal.

Aortic dissection is a rare and potentially fatal disease, with an estimated incidence of 5-30 cases per million per year. ${ }^{[1]}$ Classically, aortic dissection presents with sudden and severe pain in the chest, back, or abdomen. Patients often describe tearing or ripping pain radiating to the interscapular region. There are a few reports of atypical findings or no pain in the literature. Cerebral ischemic complications occur in $18-30 \%$ of aortic dissections. ${ }^{[2]}$ They result from occlusion of the origin of the common carotid by dissection flap or due to artery-to-artery embolism from a thrombus developed on the intimal surface of the dissected artery. ${ }^{[3]}$ Chronic systemic hypertension is the most common risk factor, followed by connective tissue diseases such as Marfans syndrome and Ehlers Danlos syndrome. ${ }^{[4]}$ Our patient had no clinical signs of connective tissue disease. One unique finding in this patient was the presence of normal peripheral pulses. The diagnosis was made by a combination of clinical suspicion, echocardiography, and MR aortogram. Aortic dissection has varied presentations and requires a high degree of clinical suspicion for an early and accurate diagnosis.

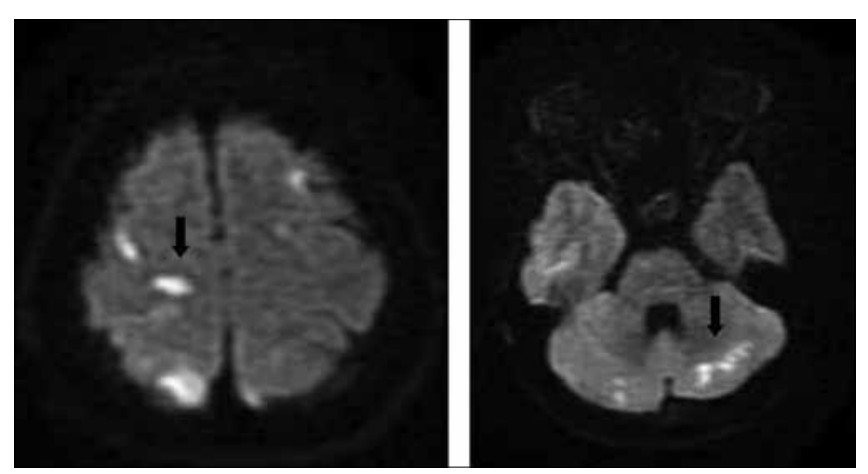

Figure 1: MR diffusion showing acute infarcts
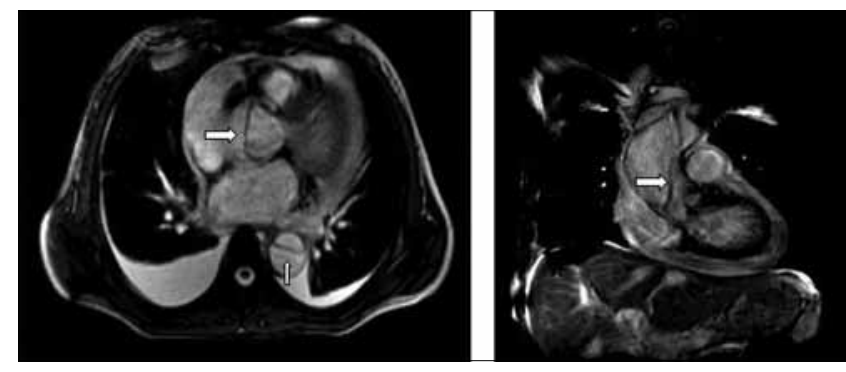

Figure 2: Magnetic resonance imaging of thorax showing dissecting flap in the aorta (white arrow), causing "double lumen"

Address for correspondence:

Dr. Thomas Mathew,

Department of Neurology, St. Johns Medical College and Hospital, Bangalore - 560 034, India.

E-mail: chakkuthom@hotmail.com

PMID: 19934585

DOI: $10.4103 / 0028-3886.57784$

\section{References}

1. Baydin A, Nargis C, Nural MS, Aygun D, Karatas AD, Bahcivan M. Painless, acute aortic dissection presenting as an acute stroke. Mt Sinai J Med 2006;73:1129-31.

2. Gaul C, Dietrich W, Friedrich I, Sirch J, Erbguth FJ. Neurological symptoms in type A aortic dissection. Stroke 2007; 38: 292-7.

3. Veyssier-Belot C, Cohen A, Rougemont D, Levy C, Amarenco P, Bousser MG. Cerebral infaretion due to painless thoracic aortic and common carotid artery dissections. Stroke 1993;24;2111-3.

4. Pumphrey CW, Fay T, Weir I. Aortic dissection during pregnancy. Br Heart J 1986;55:106-8.

Accepted on 02-07-2009

Source of Support: Nil, Conflict of Interest: None declared. 